\title{
BMJ Open Real-world, single-centre prospective data of age at breast cancer onset: focus on survival and reproductive history
}

\author{
Peeter Karihtala (iD , ${ }^{1}$ Anniina Jääskeläinen, ${ }^{2}$ Nelli Roininen, ${ }^{2}$ Arja Jukkola ${ }^{3}$
}

To cite: Karihtala $P$, Jääskeläinen $\mathrm{A}$, Roininen $\mathrm{N}$, et al. Real-world, singlecentre prospective data of age at breast cancer onset: focus on survival and reproductive history. BMJ Open 2021;11:e041706. doi:10.1136/ bmjopen-2020-041706

- Prepublication history for this paper is available online. To view these files, please visit the journal online (http://dx.doi. org/10.1136/bmjopen-2020041706).

Received 15 June 2020 Revised 08 January 2021 Accepted 13 January 2021

\section{Check for updates}

C Author(s) (or their employer(s)) 2021. Re-use permitted under CC BY-NC. No commercial re-use. See rights and permissions. Published by BMJ.

${ }^{1}$ Department of Oncology, Helsinki University Hospital Comprehensive Cancer Centre, University of Helsinki, Helsinki, Finland

${ }^{2}$ Department of Oncology and Radiotherapy, Medical Research Center Oulu, Oulu University Hospital and University of Oulu, Oulu, Finland

${ }^{3}$ Department of Oncology and Radiotherapy, Faculty of Medicine and Health Technology, Tampere University Hospital, Tampere University, Tampere, Finland

Correspondence to Dr Peeter Karihtala; peeter.karihtala@helsinki.fi

\section{ABSTRACT}

Objectives Being either young or old at the time of breast cancer diagnosis has been suggested as an indicator of a poor prognosis. We studied the effect of age at breast cancer onset in relation to survival, focusing in particular on biological subtypes and reproductive anamnesis. Design, setting and participants Patients with early breast cancer $(n=594)$ treated in a Finnish University Hospital during 2003-2013 were prospectively collected and followed in median 102 months.

Results Patients with luminal A-like breast cancer were older than the patients with luminal B-like (HER2-positive) $(p=0.045)$ or patients with the HER2-positive (nonluminal) subtype ( $p=0.029$ ). Patients $\geq 70$ years received substantially less adjuvant chemotherapy $\left(p=1.5 \times 10^{-9}\right)$ and radiotherapy $\left(p=5.9 \times 10^{-7}\right)$ than younger women. Nevertheless, the estimated 10-year breast cancerspecific rates of survival were $84.2 \%, 92.9 \%$ and $87.0 \%$ in age groups $<41$ years, $41-69$ years and $\geq 70$ years, respectively, with no statistical difference $(p=0.115)$. Survival rates were also comparable between the three age groups when assessed separately in different biological subtypes, and for patients with metastatic breast cancer there was similarly no difference between the age groups. Later menarche $\left(p=5.7 \times 10^{-8}\right)$ and high parity $(p=0.000078)$ correlated with increased age at breast cancer diagnosis, but, according to the patients' oestrogen receptor (ER) status, only among ER-positive patients. Conclusions Despite the suggested undertreatment of older patients, we report excellent long-term outcomes in all age groups in this prospective cohort. Later endogenous endocrine exposure may cause delay in breast cancer onset, but the exact biology behind this phenomenon is so far unclear.

\section{INTRODUCTION}

Age is a very strong risk factor for breast cancer. ${ }^{1}$ Prolonged endogenous oestrogen exposure, such as early menarche, late menopause or a low number of deliveries, leads to increased breast mitotic activity and a higher probability of tumorigenic somatic events, which are subsequently also important breast cancer risk factors. ${ }^{2} 3$ Young patients with breast cancer (<35 years) have biologically more aggressive breast cancers, with a higher proportion of oestrogen receptor (ER)-negative, high-grade cancers. These

\section{Strengths and limitations of this study}

This was a study of contemporary, prospective breast cancer cohort in a university hospital with a relatively long follow-up.

- The material did not include patients with de novo metastatic breast cancer.

- The number of patients with the certain breast cancer subtypes could have been larger to make more detailed subgroup analyses possible.

women may, consequently, have poorer outcomes than older patients, and this difference remains even after the adjustment of prognostic factors. ${ }^{45}$ On the other hand, there are convincing data that patients with breast cancer $>65$ years old have a shortened survival because the cancer is at a later stage at diagnosis and less intensive treatments are offered. ${ }^{6}$

In 2000, Perou et $a l^{7}$ classified breast carcinomas into four 'intrinsic' subtypes with gene expression profiling. Although still a largely simplified version of the real heterogeneity, invasive breast cancer is nowadays most commonly categorised into five subtypes: luminal A-like, luminal B-like (HER2-negative), luminal B-like (HER2positive), triple-negative or HER2-positive (non-luminal), which differ in terms of both their molecular constitutions and patient outcomes. These subtypes can be classed rather reliably using immunohistochemical (IHC) surrogates, according to the European Society for Medical Oncology (ESMO) 2015 Early Breast Cancer Clinical Practice Guidelines. ${ }^{8}$ There is some evidence that age as a prognostic factor in breast cancer is dependent on biological subtype, ${ }^{910}$ as, for example, young age has been associated with a poorer outcome, especially in luminal subtypes. ${ }^{9}$

Since most previous studies assessing age as a prognostic factor have used cohorts from the 20th century, we wanted to evaluate the age at breast cancer onset and its relation to 
biological subtypes, traditional prognostic factors and survival in a modern, prospective cohort from a university hospital. Special emphasis was given to the possible relationship between reproductive factors, such as age at menarche, number of deliveries and age at menopause, and the age at breast cancer onset.

\section{METHODS}

Patient data for this study were prospectively collected at Oulu University Hospital in 2003-2013. All women $(\mathrm{n}=594)$ had been diagnosed with early, invasive breast cancer and they at least began to receive treatment at Oulu University Hospital (table 1). Patients with previous breast cancer diagnoses or distant metastases at the time of diagnosis were excluded from the study to avoid the possibility of local recurrences misdiagnosed as new breast cancers.

Tumours were classed into five intrinsic subtypes according to the ESMO Early Breast Cancer Clinical Practice Guidelines. ${ }^{8}$ Luminal A-like carcinomas expressed both ER and progesterone receptors (PR), but HER2 was not overexpressed and Ki-67 was expressed in $<15 \%$ of their cells. Luminal B-like (HER2-negative) carcinomas were also ER-positive and HER2-negative, but they either showed Ki-67 expression in $>15 \%$ of their cells or were PR-negative. Luminal B-like (HER2-positive) carcinomas still expressed ER, but they also overexpressed HER2. Triple-negative breast cancers (TNBCs) were defined as tumours with no expression of ER, PR and HER2. HER2positive (non-luminal) cases overexpressed HER2 but did not express either ER or PR.

Histopathology was assessed according to current WHO classifications, and the tumour stage was evaluated according to the TNM Classification of Malignant Tumours. ${ }^{11}$ The expressions of ER, PR and Ki-67 were assessed using the IHC methods previously described. ${ }^{12}$ HER2 expression was then assessed using IHC and chromogenic in situ hybridisation (CISH) to confirm any positive results. Any sample with a positive result of six or more gene copies according to CISH was considered to be HER2-positive. ${ }^{13}$

\section{Statistical analyses}

Statistical analyses were performed using SPSS Statistics software V.25.0 for Mac (IBM Corporation). In the analyses, age was assessed mainly using three age classes as parameters: $<41$ years, $41-69$ years and $\geq 70$ years. In addition, age was correlated as a continuous variable with other continuous variables of reproductive history (parity, age at menarche and menopausal age). Survival was analysed using Kaplan-Meier curves and the log-rank test. Breast cancer-specific survival (BCSS) was calculated from the date of surgical tumour removal to the time of breast cancer-related death or the end of follow-up. Relapse-free survival (RFS) was calculated from the date of the operation to the date of the first confirmed local relapse in ipsilateral or contralateral axilla, scar or breast.
Distant disease-free survival (DDFS) was calculated from the date of the operation to the date of the first confirmed distant relapse. Survival with metastatic breast cancer was calculated from the time of distant metastases diagnosis to the time of breast cancer-related death or the end of follow-up. Prognostic factors were reformatted as two-class variables for the analyses. Multivariate analyses were conducted using Cox multivariate regression analyses, where the covariates were tumour size and nodal status; tumour sizes were assessed as either T1 or T2-4 and nodal status was categorised as either N0 or N1-3. Cross-tabulation was used to compare the groups and twosided Pearson's $X^{2}$ test or Fisher's exact test was used, as applicable, to determine significance. Continuous variables were assessed using Pearson correlation, the MannWhitney $\mathrm{U}$ test or the Kruskal-Wallis test. $\mathrm{P}$ values $<0.05$ were considered significant.

\section{Data accessibility}

The data that support the findings of this study are available from the corresponding author on reasonable request.

\section{Patient and public involvement}

Patients or the public were not involved in the design, conduct, reporting or dissemination of this study.

\section{RESULTS}

The median age at breast cancer onset was 58 years (range 28-87 years) and median follow-up time was 102.0 months (mean 103.9 months). The median survival with metastatic breast cancer was 18.0 months (mean 30.2 months). The median age at menarche was 13.0 years (range 10.0-17.0 years) and median menopause age 50.0 years (range 37.0-60.0 years). The median number of deliveries at the time of breast cancer diagnosis was 2 (range $0-10$ ).

Among the women $<41$ years, median menopause age was 12.0 years and the median number of deliveries was 2. There were no menopauses at time of time of breast cancer diagnosis in this age group. Among women aged 41-69 years, the median age at menarche was 13.0 years, median menopause age was 50.0 years and the median number of deliveries was 2. These figures for women $\geq 70$ years were 14.0 years, 52.0 years and 2 deliveries, respectively.

There were $35(5.9 \%)$ local recurrences, 61 (10.3\%) distant metastases and $50(8.4 \%)$ breast cancer-related deaths during the follow-up. The majority of patients received adjuvant chemotherapy, endocrine therapy and radiotherapy (table 1). All 61 HER2-positive patients received trastuzumab in adjuvant setting. Of those receiving adjuvant endocrine therapy, 166 (42.1\%) received tamoxifen and $222(56.3 \%)$ aromatase inhibitor, and in $6(1.5 \%)$ patients the exact adjuvant endocrine therapy was uncertain. Age at breast cancer onset was not associated with the first site of distant recurrence. 
Table 1 Comparison of treatments and clinical and pathological characteristics of tumours according to age at breast cancer diagnosis

\begin{tabular}{|c|c|c|c|c|c|}
\hline & Total & $<41$ years & 41-69 years & $\geq 70$ years & $P$ value \\
\hline Number of patients & 594 & $37(6.2 \%)$ & $472(79.5 \%)$ & 85 (14.3\%) & \\
\hline Tumour size & & & & & 0.1 (T1 vs T2-4) \\
\hline T1 & $384(64.6 \%)$ & $20(54.1 \%)$ & $315(66.7 \%)$ & $49(57.6 \%)$ & \\
\hline $\mathrm{T} 2$ & $189(31.8 \%)$ & $14(37.8 \%)$ & $144(30.5 \%)$ & $31(36.5 \%)$ & \\
\hline T3 & $19(3.2 \%)$ & $3(8.1 \%)$ & $12(2.5 \%)$ & $4(4.7 \%)$ & \\
\hline $\mathrm{T} 4$ & $2(0.3 \%)$ & $0(0 \%)$ & $1(0.2 \%)$ & $1(1.2 \%)$ & \\
\hline Nodal status & & & & & 0.5 (N0 vs N1-3) \\
\hline NO & $368(62.0 \%)$ & $21(56.8 \%)$ & $298(63.1 \%)$ & 49 (57.6\%) & \\
\hline N1 & $162(27.3 \%)$ & $10(27.0 \%)$ & $125(26.5 \%)$ & 27 (31.8\%) & \\
\hline N2 & $50(8.4 \%)$ & $4(10.8 \%)$ & $40(8.5 \%)$ & $6(7.1 \%)$ & \\
\hline N3 & $14(2.4 \%)$ & $2(5.4 \%)$ & $9(1.9 \%)$ & $3(3.5 \%)$ & \\
\hline Histopathology & & & & & 0.040 \\
\hline Ductal & $456(76.8 \%)$ & $30(81.1 \%)$ & $368(78.0 \%)$ & $58(68.2 \%)$ & \\
\hline Lobular & $91(15.3 \%)$ & $3(8.1 \%)$ & $74(15.7 \%)$ & $14(16.5 \%)$ & \\
\hline Other & 47 (7.9\%) & $4(10.8 \%)$ & $30(6.4 \%)$ & $13(15.3 \%)$ & \\
\hline Multifocal cancer & & & & & 0.57 \\
\hline Yes & $122(20.5 \%)$ & 7 (18.9\%) & $101(21.4 \%)$ & $14(16.5 \%)$ & \\
\hline No & 472 (79.5\%) & $30(81.1 \%)$ & $371(78.6 \%)$ & $71(73.5 \%)$ & \\
\hline Bilateral cancer & & & & & 0.77 \\
\hline Yes & $16(2.7 \%)$ & $1(2.7 \%)$ & $11(2.3 \%)$ & $4(4.7 \%)$ & \\
\hline No & $578(97.3 \%)$ & $36(97.3 \%)$ & $461(97.7 \%)$ & $81(95.3 \%)$ & \\
\hline Histopathological grade & & & & & 0.014 (grade I-II vs grade III) \\
\hline Grade 1 & $103(17.3 \%)$ & $4(10.8 \%)$ & $82(17.9 \%)$ & $17(21.3 \%)$ & \\
\hline Grade 2 & $293(49.3 \%)$ & $14(37.8 \%)$ & $239(52.2 \%)$ & $40(50.0 \%)$ & \\
\hline Grade 3 & $179(30.1 \%)$ & $19(51.4 \%)$ & $137(29.0 \%)$ & $23(27.1 \%)$ & \\
\hline Unknown & $19(3.2 \%)$ & $0(0 \%)$ & $14(3.0 \%)$ & $5(5.9 \%)$ & \\
\hline ER expression & & & & & 0.000009 (negative vs positive) \\
\hline Negative (0\%) & $92(15.5 \%)$ & $16(43.2 \%)$ & $65(13.8 \%)$ & $11(12.9 \%)$ & \\
\hline Weak (1\%-9\%) & $18(3.0 \%)$ & $1(2.7 \%)$ & $15(3.2 \%)$ & $2(2.4 \%)$ & \\
\hline Moderate (10\%-59\%) & $26(4.4 \%)$ & $1(2.7 \%)$ & $21(4.4 \%)$ & $4(4.7 \%)$ & \\
\hline High (>59\%) & $455(76.6 \%)$ & $19(51.4 \%)$ & $370(78.4 \%)$ & $66(77.6 \%)$ & \\
\hline Unknown & $3(0.5 \%)$ & $0(0 \%)$ & $1(0.2 \%)$ & $2(2.4 \%)$ & \\
\hline PR expression & & & & & 0.025 (negative vs positive) \\
\hline Negative $(0 \%)$ & $146(24.6 \%)$ & $16(43.2 \%)$ & $110(23.3 \%)$ & $20(23.5 \%)$ & \\
\hline Weak (1\%-9\%) & $81(13.6 \%)$ & $2(5.4 \%)$ & $68(14.4 \%)$ & $11(12.9 \%)$ & \\
\hline Moderate (10\%-59\%) & 65 (10.9\%) & $4(10.8 \%)$ & $50(10.6 \%)$ & $11(12.9 \%)$ & \\
\hline High (>59\%) & $298(50.2 \%)$ & $15(40.5 \%)$ & $242(51.3 \%)$ & $41(48.2 \%)$ & \\
\hline Unknown & $4(0.7 \%)$ & $0(0 \%)$ & $2(0.4 \%)$ & $2(2.4 \%)$ & \\
\hline HER2 status & & & & & 0.36 \\
\hline HER2-negative & $533(89.7 \%)$ & $33(89.2 \%)$ & $420(89.0 \%)$ & $80(94.1 \%)$ & \\
\hline HER2-positive (CISH) & $61(10.3 \%)$ & $4(10.8 \%)$ & $52(11.0 \%)$ & 5 (5.9\%) & \\
\hline Ki-67 expression & & & & & $0.0012(0 \%-14 \%$ vs $>14 \%)$ \\
\hline Negative $(<5 \%)$ & $41(6.9 \%)$ & $2(5.4 \%)$ & $32(6.8 \%)$ & 7 (8.2\%) & \\
\hline Weak (5\%-14\%) & 268 (45.1\%) & $7(18.9 \%)$ & $220(46.6 \%)$ & $41(48.2 \%)$ & \\
\hline
\end{tabular}




\begin{tabular}{|c|c|c|c|c|c|}
\hline & Total & $<41$ years & $41-69$ years & $\geq 70$ years & $P$ value \\
\hline Moderate $(15 \%-30 \%)$ & $141(23.7 \%)$ & $9(24.3 \%)$ & $111(23.5 \%)$ & $21(24.7 \%)$ & \\
\hline High (>30\%) & $136(22.9 \%)$ & $19(51.4 \%)$ & $104(22.0 \%)$ & $13(15.3 \%)$ & \\
\hline Unknown & $8(1.3 \%)$ & $0(0 \%)$ & $5(1.0 \%)$ & $3(3.5 \%)$ & \\
\hline Subtype & & & & & 0.00011 \\
\hline Luminal A-like & $271(46.2 \%)$ & $9(24.3 \%)$ & $220(46.6 \%)$ & $42(49.4 \%)$ & \\
\hline Luminal B-like (HER2-negative) & $192(32.8 \%)$ & $11(29.7 \%)$ & $156(33.1 \%)$ & $25(29.4 \%)$ & \\
\hline Luminal B-like (HER2-positive) & $33(5.6 \%)$ & $1(2.7 \%)$ & $28(5.9 \%)$ & $4(4.7 \%)$ & \\
\hline HER2-positive (non-luminal) & $27(4.5 \%)$ & $3(8.1 \%)$ & $23(4.9 \%)$ & $1(1.2 \%)$ & \\
\hline Triple-negative & $63(10.8 \%)$ & $13(35.1 \%)$ & $40(8.5 \%)$ & $10(11.8 \%)$ & \\
\hline Unknown & $8(1.3 \%)$ & $0(0 \%)$ & $5(1.1 \%)$ & $3(3.5 \%)$ & \\
\hline Adjuvant chemotherapy & & & & & $1.5 \times 10^{-9}$ \\
\hline Yes & 347 (58.4\%) & $32(86.5 \%)$ & $289(61.2 \%)$ & $26(30.6 \%)$ & \\
\hline No & $247(41.6 \%)$ & $5(13.5 \%)$ & $183(38.8 \%)$ & $59(69.4 \%)$ & \\
\hline \multicolumn{3}{|l|}{ Taxane-based adjuvant chemotherapy } & & & 0.0097 \\
\hline Yes & $190(55.1 \%)$ & $25(78.1 \%)$ & $156(54.4 \%)$ & $9(34.6 \%)$ & \\
\hline No & $146(42.3 \%)$ & $7(21.9 \%)$ & $122(42.5 \%)$ & $17(65.4 \%)$ & \\
\hline Unknown & $9(2.6 \%)$ & $0(0 \%)$ & $9(3.1 \%)$ & $0(0 \%)$ & \\
\hline Adjuvant radiotherapy & & & & & $5.9 \times 10^{-7}$ \\
\hline Yes & $514(86.5 \%)$ & $34(91.9 \%)$ & $472(89.4 \%)$ & $58(68.2 \%)$ & \\
\hline No & $80(13.5 \%)$ & $3(8.1 \%)$ & $50(10.6 \%)$ & $27(31.6 \%)$ & \\
\hline Adjuvant endocrine therapy & & & & & 0.060 \\
\hline Yes & $391(65.8 \%)$ & $18(48.6 \%)$ & $319(67.6 \%)$ & $54(63.5 \%)$ & \\
\hline No & $200(33.7 \%)$ & $18(48.6 \%)$ & $151(32.0 \%)$ & $31(36.5 \%)$ & \\
\hline Unknown & $3(0.5 \%)$ & $1(2.7 \%)$ & $2(0.4 \%)$ & $0(0 \%)$ & \\
\hline
\end{tabular}

$\mathrm{CISH}$, chromogenic in situ hybridisation; ER, oestrogen receptor; PR, progesterone receptor.

Older age at breast cancer diagnosis correlated very closely with high parity $(\mathrm{p}=0.000078$; correlation coefficient 0.17$)$ and increased age at menarche $\left(\mathrm{p}=5.7 \times 10^{-8}\right.$; correlation coefficient 0.25 ; figure 1 ). To a lesser extent, older age at diagnosis correlated with increased menopausal age $(p=0.018$; correlation coefficient 0.15$)$. When

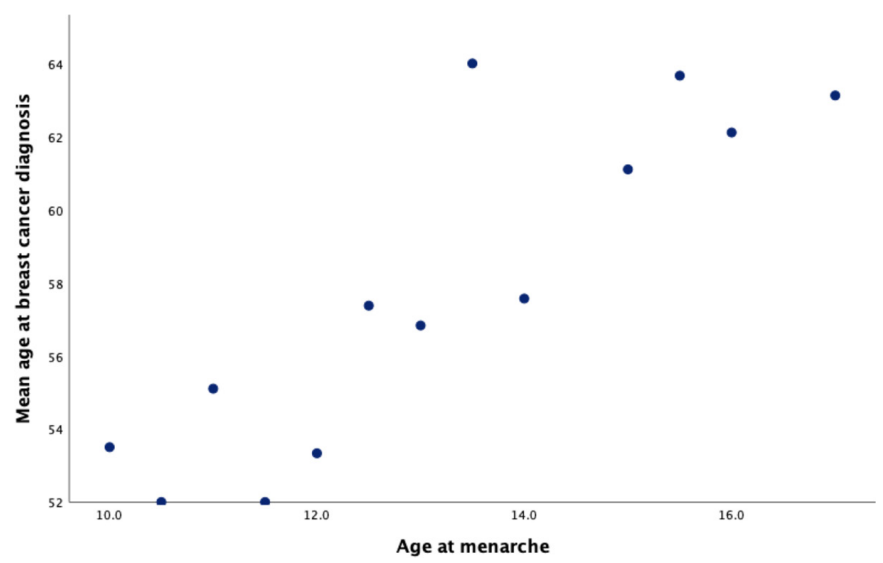

Figure 1 Age at menarche is strictly correlated with age at breast cancer diagnosis. data were split according to the ER status, increased age correlated with high parity $(\mathrm{p}=0.00030$; correlation coefficient 0.17$)$, increased age at menarche $(p=0.000002$; correlation coefficient 0.24 ) and later menopause ( $p=0.013$; correlation coefficient 0.17 ) among ER-positive patients only.

The median age at patients with breast cancer onset in luminal A-like was 58.0 years, luminal B-like (HER2negative) 58.0 years, HER2-positive (non-luminal) 56.0 years, luminal B-like (HER2-positive) 53 years and 56.0 years in patients with TNBC (figure 2). When compared in pairs, the patients with luminal A-like breast cancer were older than the patients with luminal B-like (HER2positive) $(\mathrm{p}=0.045)$ subtype or patients with HER2positive (non-luminal) subtype $(\mathrm{p}=0.029)$. Additionally, women with luminal A-like breast cancers tended to be older than those with TNBC, but this was not a formally significant finding $(\mathrm{p}=0.081)$.

\section{Age at breast cancer onset and survival}

BCSS, DDFS, RFS or survival with metastatic breast cancer did not differ statistically significantly between the three age groups (figure 3 ). Similarly, no statistically significant 


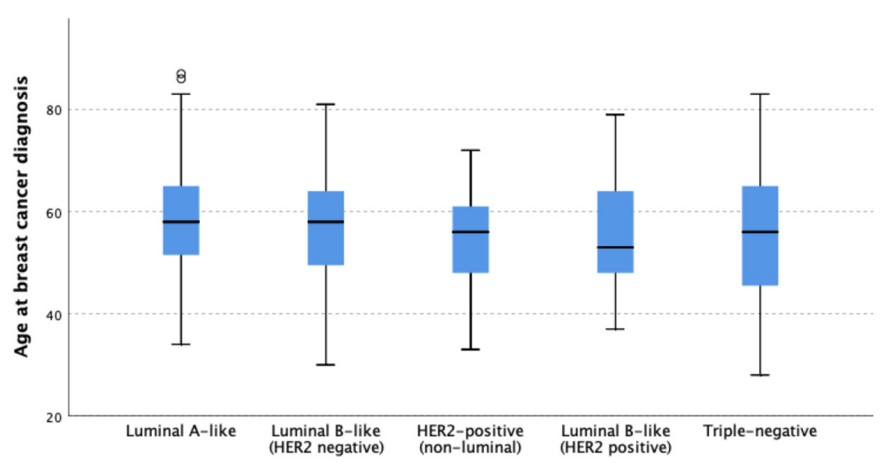

Figure 2 The distribution of breast cancer subtypes and age at diagnosis. When subtypes are compared in pairs, women with luminal A-like breast cancer are older than women with the luminal B-like (HER2-positive) $(p=0.045)$ or those with the HER2-positive (non-luminal) subtype $(p=0.029)$. The black line indicates median age, the blue boxes represent 25th and 75th percentiles, whiskers show variability outside the upper and lower quartiles, and circles represent outlier values.

differences were found when age groups were compared in pairs. Five-year estimated BCSS rates were 94.6\%, $96.5 \%$ and $92.6 \%$, and 10 -year estimated BCSS rates were $84.2 \%, 92.9 \%$ and $87.0 \%$ in the age groups of $<41$ years, $41-69$ years and $\geq 70$ years, respectively.

Survival between the age groups was not statistically significantly different, when analysis was done separately in different biological subtypes. We also conducted a survival analysis according to ER and HER2 status, without taking Ki-67 into account. Although in the group of ER-positive and HER2-negative patients, BCSS and DDFS were shorter in $<41$-year-old women $(\mathrm{p}=0.042$ and $p=0.029$, respectively), these differences were not significant in multivariate analysis.

The traditional prognostic factors, such as tumour size, nodal status, proliferation or intrinsic subtype, had a prognostic value (BCSS) of similar magnitude, when studied separately in the three age groups (data not shown). However, smaller number of patients limited the reliability of the analysis in $<41$-year-old women.

\section{DISCUSSION}

In this contemporary, prospective cohort of 594 women with early breast cancer, comparable survival rates between the age groups of $<41$ years, $41-69$ years and $\geq 70$ years are reported. Stratification by breast cancer biological subtype did not affect the survival results. Another main result from the data was that later menarche or an increased number of deliveries was very closely correlated with older age at breast cancer diagnosis.

Breast cancer onset is proportional to the median age of the underlying population at risk. ${ }^{14}$ In this prospective study, the material median age at breast cancer diagnosis was 58.0 years, in line with most reports from Western countries with mammography screenings. ${ }^{15} 16$ It has been reported that both young and old age at breast cancer onset indicates a poorer prognosis, compared with 'middle-aged' women, ${ }^{17} 18$ although this observation has not been present unanimously in all studies. ${ }^{19}{ }^{20}$ In addition, in the present work, the 'middle-aged' group of women (41-69 years old) had a statistically non-significant trend of the best BCSS and DDFS rates. Excellent BCSS rates in all age groups (10-year Kaplan-Meier estimate $91.4 \%$ in the whole cohort) may partly explain why larger differences between the groups were demonstrated in our study. Indeed, the survival rates were significantly better than reported in most previous studies assessing age and breast cancer prognosis. In a large Swedish cohort study, women either under 40 years or at least 80 years at diagnosis had the worst prognosis, while in the whole population, 10-year BCSS was slightly over 70\%. ${ }^{17}$ An Australian study, which used the same three age groups as we did, reported 10-year survival rates as low as $49 \%$ in women $<40$ years, while women aged 40-69 at diagnosis had a 10 -year survival rate of $73 \% .^{21}$

Less frequent use of adjuvant (chemo)therapies and less optimal surgery due to comorbidities may at least partially explain the poorer prognosis of the elderly observed previously. ${ }^{522} 23$ Younger women are likely to receive more intensive treatments, but they also have a tendency to develop more aggressive breast cancer subtypes. ${ }^{24}{ }^{25}$ In our cohort, almost $70 \%$ of patients $\geq 70$ years did not receive adjuvant chemotherapy compared with fewer than $15 \%$ of women $<41$ years. Also, radiotherapy was considerably less frequently administered in older women. These differences may be due to frailty caused by many comorbidities and poor performance status among older women, which were not investigated in our study. The youngest patients had also more aggressive biological subtypes compared with the oldest patients, but these differences are small to explain all discrepancies in the administration of adjuvant chemotherapy. Moreover, the oldest patients experienced more mastectomies and hence received less radiotherapy. On the other hand, all HER2-positive patients received trastuzumab as an adjuvant therapy. Since prognosis did not differ between the age groups in the current study, despite significant differences in the use of adjuvant treatments, there is a possibility that younger patients were overtreated, rather than that older patients were undertreated.

It has been proposed that the effect of age on survival may vary by breast cancer subtype. A large longitudinal cohort study provided evidence that women 40 years old or younger had worse BCSS, but only if they had luminal A-like tumours, determined in that study as ER-positive and/or PR-positive, HER2-negative and low/ intermediate-grade tumours. ${ }^{9}$ In a retrospective study by Liu et al, ${ }^{10}$ the authors used almost the same criteria for biological subtypes as in the current study, concluding that the patients $<41$ years old at diagnosis had worse disease-free survival or DDFS, but only if the patients had luminal A-like breast cancer. Similarly, an age of $<41$ years was found to be an adverse prognostic factor in luminal A-like or luminal B-like cancers. ${ }^{26}$ We found that luminal A-like cancers were over-represented among the oldest 

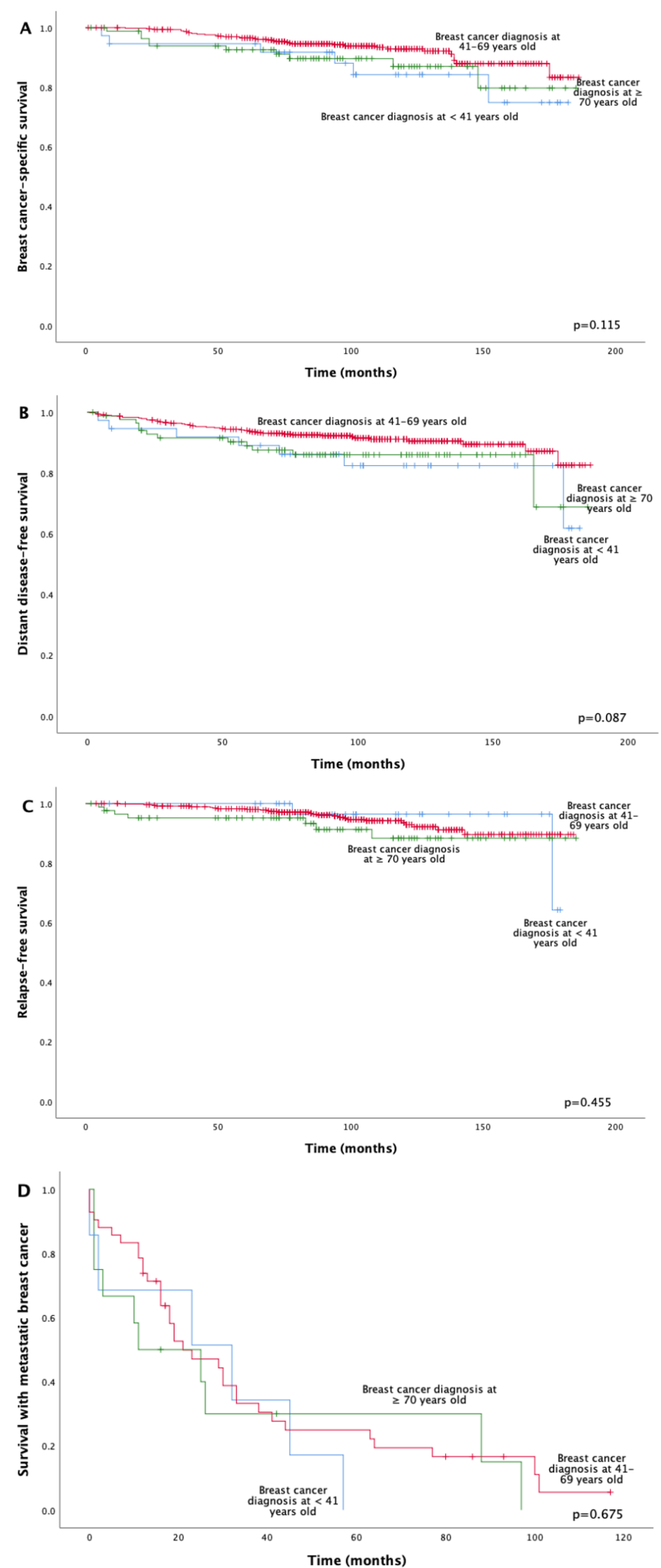

Figure 3 Kaplan-Meier plot for breast cancer-specific survival (A), distant disease-free survival (B), local relapse-free survival (C), survival with metastatic disease (D), compared between different ages at disease onset. In all figures, the blue line represents women who have been diagnosed under 41 years old, the red line women diagnosed at 41-69 years old and the green line women diagnosed at 70 years old or older. 
women compared with HER2-positive (luminal or nonluminal) subtypes, independently of whether age was handled in analysis as a three-class factor or as a continuous factor. This over-representation of HER2-positive subtypes and under-representation of luminal A-like cancers among the youngest patients with breast cancer has been known for some time. ${ }^{27}{ }^{28}$ Young age was not an adverse prognostic factor in our study either, if assessed separately in different biological subtypes. Nevertheless, our data consisted of only nine women $<41$ years old with luminal A breast cancer and thus no definite conclusions from this group can be drawn. Although the prevalence of TNBC was three times more frequent among the women $<41$ years old compared with older age groups, this observation was not formally significant according to our statistical plan, in which we assessed age as a continuous factor. Given that more than $20 \%$ of women with a triple-negative phenotype carry a BRCA1 mutation, it would have been interesting to know the BRCA status of our patients, which unfortunately was not available. ${ }^{29}$

Regarding the whole cohort, without analysing different age subgroups, we have recently published the long-term survival results according to the intrinsic subgroups and traditional prognostic factors. ${ }^{30}$ These results were well in line with the published literature, which supports the representativeness of the current material in comparison with previous studies.

Sixty-one of our patients had distant recurrence during follow-up. Survival with metastatic breast cancer was similar in all three age groups, although the low number of events, especially in the youngest and oldest subgroups, may decrease the reliability of this analysis. Previous larger studies with only patients with metastatic breast cancer have reported conflicting results regarding the association between age and survival. ${ }^{31} 32$

Classifying a continuous variable such as age as a class variable always somewhat distorts biological phenomena. We used three age classes, <41 years, 41-69 years and $\geq 70$ years, based on previous studies and also because we considered this classification as the most clinically relevant. This was also a practical issue in this material, since if the cut-off for being young would have been 35 years old and the cut-off of being old would have been 75 years old, the sample sizes in these cohorts would have been only 14 and 38 patients, respectively. BRCA1/2 mutations have been found to be much more common if the breast cancer was diagnosed in the 30-35 year-age group compared with 40 years of age at disease onset. ${ }^{33}$ Also, the oldest of the elderly patients with breast cancer had different clinicopathological profiles from those of the patients aged 70-79 years old, including a more advanced stage, lower grade and increased oestrogen sensitivity. ${ }^{345}$ In our data, there were no significant differences in tumour size or nodal status between the three age groups.

Early menarche is a well-known risk factor especially for ER-positive breast cancers, although its effect is relatively small, approximately $5 \%$ for every year younger at menarche. ${ }^{2}$ Parity first increases breast cancer risk for
5-10 years after pregnancy, but then offers a lifelong protective effect. ${ }^{36}$ We observed that late menopause and increased parity, together with increased age at menarche, correlated with breast cancer diagnosis in older age. It is plausible that the breast cancer risk is postponed in these women, along with their delayed oestrogen exposure, but the strength of these correlations was still unexpected. Underlining the endocrine effect behind these correlations, they were observed only within ER-positive patients. To the best of our knowledge, this topic has been previously assessed only to a limited extent and our report is the first prospective study to find evidence for this correlation. Similarly to our study, among BRCA1/2 mutation carriers, nulliparity was associated with earlier breast cancer onset. ${ }^{37}$ Feng et $a l,{ }^{38}$ using a large Chinese database, found that postmenopausal patients with breast cancer experienced menarche later than premenopausal patients with breast cancer, although the exact age at breast cancer onset was unknown in this study. As a pitfall of the current study design, we did not have access to some important lifestyle-related factors, such as weight, physical activity or diet. These potential confounding factors are known as risk factors for poorer breast cancer outcomes, but they also associate with reproductive factors.

In conclusion, we report excellent long-term outcomes for women with early breast cancer in all age groups in this prospective real-world cohort, despite the fact that older patients received less intensive adjuvant treatments. Our data also indicate that postponed endogenous endocrine exposure may cause delay in the onset of first breast cancer, although proving causality requires further confirmatory studies and the exact biology behind this phenomenon is still uncertain.

Contributors All authors contributed to the study design and conception. AJ initiated the collection of the prospective dataset. PK, AJ and NR were responsible for assessing statistical analyses. PK was a major contributor in writing the manuscript. All authors provided comments on drafts of the manuscript. All authors read and approved the final manuscript.

Funding The authors have not declared a specific grant for this research from any funding agency in the public, commercial or not-for-profit sectors.

Competing interests None declared.

Patient and public involvement Patients and/or the public were not involved in the design, or conduct, or reporting, or dissemination plans of this research.

Patient consent for publication Not required.

Ethics approval The patients provided their written informed consent to participate in the study, which was approved by the Local Ethics Committee of the Ostrobothnia Hospital District (114/2011) and the National Supervisory Authority for Welfare and Health (D9580/05.01.00.06/2010).

Provenance and peer review Not commissioned; externally peer reviewed.

Data availability statement Data are available upon reasonable request. The data that support the findings of this study are available from the corresponding author upon reasonable request.

Open access This is an open access article distributed in accordance with the Creative Commons Attribution Non Commercial (CC BY-NC 4.0) license, which permits others to distribute, remix, adapt, build upon this work noncommercially, and license their derivative works on different terms, provided the original work is properly cited, appropriate credit is given, any changes made indicated, and the use is non-commercial. See: http://creativecommons.org/ licenses/by-nc/4.0/. 
ORCID iD

Peeter Karihtala http://orcid.org/0000-0003-3490-3702

\section{REFERENCES}

1 Siegel RL, Miller KD, Jemal A. Cancer statistics, 2020. CA Cancer J Clin 2020;70:7-30.

2 Collaborative Group on Hormonal Factors in Breast Cancer. Menarche, menopause, and breast cancer risk: individual participant meta-analysis, including 118964 women with breast cancer from 117 epidemiological studies. Lancet Oncol 2012;13:1141-51.

3 Ferguson DJ, Anderson TJ. Morphological evaluation of cell turnover in relation to the menstrual cycle in the "resting" human breast. $\mathrm{Br} J$ Cancer 1981;44:177-81.

4 Fredholm H, Eaker S, Frisell J, et al. Breast cancer in young women: poor survival despite intensive treatment. PLoS One 2009;4:e7695-9.

5 Anders CK, Hsu DS, Broadwater G, et al. Young age at diagnosis correlates with worse prognosis and defines a subset of breast cancers with shared patterns of gene expression. J Clin Oncol 2008;26:3324-30.

6 Eaker S, Dickman PW, Bergkvist L, et al. Differences in management of older women influence breast cancer survival: results from a population-based database in Sweden. PLoS Med 2006;3:e25-8.

7 Perou CM, Sørlie T, Eisen MB, et al. Molecular portraits of human breast tumours. Nature 2000;406:747-52.

8 Senkus E, Kyriakides S, Ohno S, et al. Primary breast cancer: ESMO clinical practice guidelines for diagnosis, treatment and follow-up. Ann Oncol 2015;26 Suppl 5:v8-30.

9 Partridge $\mathrm{AH}$, Hughes ME, Warner ET, et al. Subtype-Dependent relationship between young age at diagnosis and breast cancer survival. J Clin Oncol 2016;34:3308-14.

10 Liu Z, Sahli Z, Wang Y, et al. Young age at diagnosis is associated with worse prognosis in the luminal a breast cancer subtype: a retrospective institutional cohort study. Breast Cancer Res Treat 2018;172:689-702.

11 Brierley J, Gospodarowicz MK. TNM classification of malignant tumours. Berlin: Springer Science \& Business Media, 2010: 253.

12 Karihtala P, Mäntyniemi A, Kang SW, et al. Peroxiredoxins in breast carcinoma. Clin Cancer Res 2003;9:3418-24.

13 Isola J, Tanner M, Forsyth A, et al. Interlaboratory comparison of HER-2 oncogene amplification as detected by chromogenic and fluorescence in situ hybridization. Clin Cancer Res 2004;10:4793-8.

14 Bidoli E, Virdone S, Hamdi-Cherif M, et al. Worldwide age at onset of female breast cancer: a 25-year population-based cancer registry study. Sci Rep 2019;9:1-8.

15 Ginsburg O, Bray F, Coleman MP. The global burden of women's cancers: an unmet grand challenge in global health Europe PMC Funders Group. Lancet 2017;389:847-60.

16 Forman D, Bray F, Brewster DH, et al. Cancer incidence in five continents, vol. X (electronic version). Lyon, IARC, 2013. Available: http://ci5.iarc.fr

17 Brandt J, Garne J, Tengrup I, et al. Age at diagnosis in relation to survival following breast cancer: a cohort study. World J Surg Oncol 2015;13:33-11.

18 Wang M-X, Ren J-T, Tang L-Y, et al. Molecular features in young vs elderly breast cancer patients and the impacts on survival disparities by age at diagnosis. Cancer Med 2018;7:3269-77.
19 Yankaskas BC. Epidemiology of breast cancer in young women. Breast Dis 2006;23:3-8.

20 Yancik R, Wesley MN, Ries LA, et al. Effect of age and comorbidity in postmenopausal breast cancer patients aged 55 years and older. JAMA 2001;285:885-92.

21 Jayasinghe UW, Taylor R, Boyages J. Is age at diagnosis an independent prognostic factor for survival following breast cancer? ANZ J Surg 2005;75:762-7.

22 van de Water W, Markopoulos C, van de Velde CJH, et al. Association between age at diagnosis and disease-specific mortality among postmenopausal women with hormone receptor-positive breast cancer. JAMA 2012;307:590-7.

23 Bouchardy C, Rapiti E, Fioretta G, et al. Undertreatment strongly decreases prognosis of breast cancer in elderly women. J Clin Oncol 2003;21:3580-7.

24 Klauber-DeMore N. Tumor biology of breast cancer in young women. Breast Dis 2006;23:9-15.

25 Anders CK, Johnson R, Litton J, et al. Breast cancer before age 40 years. Semin Oncol 2009;36:237-49.

26 Lian W, Fu F, Lin Y, et al. The impact of young age for prognosis by subtype in women with early breast cancer. Sci Rep 2017;7:1-8.

27 Azim HA, Michiels S, Bedard PL, et al. Elucidating prognosis and biology of breast cancer arising in young women using gene expression profiling. Clin Cancer Res 2012;18:1341-51.

28 Keegan THM, Press DJ, Tao L, et al. Impact of breast cancer subtypes on 3-year survival among adolescent and young adult women. Breast Cancer Res 2013;15:R95.

29 Chen H, Wu J, Zhang Z, et al. Association between BRCA status and triple-negative breast cancer: a meta-analysis. Front Pharmacol 2018;9:1-8.

30 Jääskeläinen $A$, Roininen $N$, Karihtala $P$, et al. High parity predicts poor outcomes in patients with luminal B-like (HER2 negative) early breast cancer: a prospective Finnish single-center study. Front Oncol 2020;10:1470.

31 Alberts AS, Falkson G, van der Merwe R. Metastatic breast cancer-age has a significant effect on survival. S Afr Med J 1991;79:239-41.

32 Foukakis T, Fornander T, Lekberg T, et al. Age-specific trends of survival in metastatic breast cancer: 26 years longitudinal data from a population-based cancer registry in Stockholm, Sweden. Breast Cancer Res Treat 2011;130:553-60.

33 Malone KE, Daling JR, Neal C, et al. Frequency of BRCA1/BRCA2 mutations in a population-based sample of young breast carcinoma cases. Cancer 2000;88:1393-402.

34 Lodi M, Scheer L, Reix N, et al. Breast cancer in elderly women and altered clinico-pathological characteristics: a systematic review. Breast Cancer Res Treat 2017;166:657-68.

35 Karihtala P, Winqvist R, Bloigu R, et al. Long-term observational follow-up study of breast cancer diagnosed in women $\leq 40$ years old. Breast 2010;19:456-61.

36 Albrektsen G, Heuch I, Hansen S, et al. Breast cancer risk by age at birth, time since birth and time intervals between births: exploring interaction effects. Br J Cancer 2005;92:167-75.

37 Rieder V, Salama M, Glöckner L, et al. Effect of lifestyle and reproductive factors on the onset of breast cancer in female BRCA 1 and 2 mutation carriers. Mol Genet Genomic Med 2016;4:172-7.

38 Feng $\mathrm{F}$, Wei $\mathrm{Y}$, Zheng $\mathrm{K}$, et al. Comparison of epidemiological features, clinicopathological features, and treatments between premenopausal and postmenopausal female breast cancer patients in Western China: a retrospective multicenter study of 15,389 female patients. Cancer Med 2018;7:2753-63. 